\title{
Molinos, aljibes y norias: la cultura del paisaje en el Cabo de Gata
}

\author{
Jaime F. López Gómez \\ Eugenio Cifuentes Vélez
}

Consultores en Patrimonio

\section{Resumen}

Exponemos las características del conjunto de 145 bienes etnológicos recientemente protegidos por la Consejería de Cultura. Hacemos referencia tanto a sus principales aspectos técnicos, como, sobre todo, a su integración pasada y presente en el singular paisaje del Parque Natural del Cabo de Gata. Concluimos con unas breves reseñas de las distintas formas en que estos bienes se nos presentan en la actualidad y la difícil armonización de las distintas visiones que construyen hoy el paisaje, así como con una llamada a la necesidad de idear experiencias novedosas para resolver estas tensiones.

\section{Palabras clave}

Cabo de Gata / Protección del patrimonio / Paisaje cultural / Patrimonio etnológico / Parque Natural / Nijar / Aljibes / Norias / Molinos

El 23 de enero de 200I fueron inscritos en el Catálogo General de Patrimonio Histórico Andaluz (CGPHA) I 45 bienes etnológicos situados en el Parque Natural de Cabo de Gata-Níjar, en los munici-

1. Alijbes en el Campillo de Doña Francisca

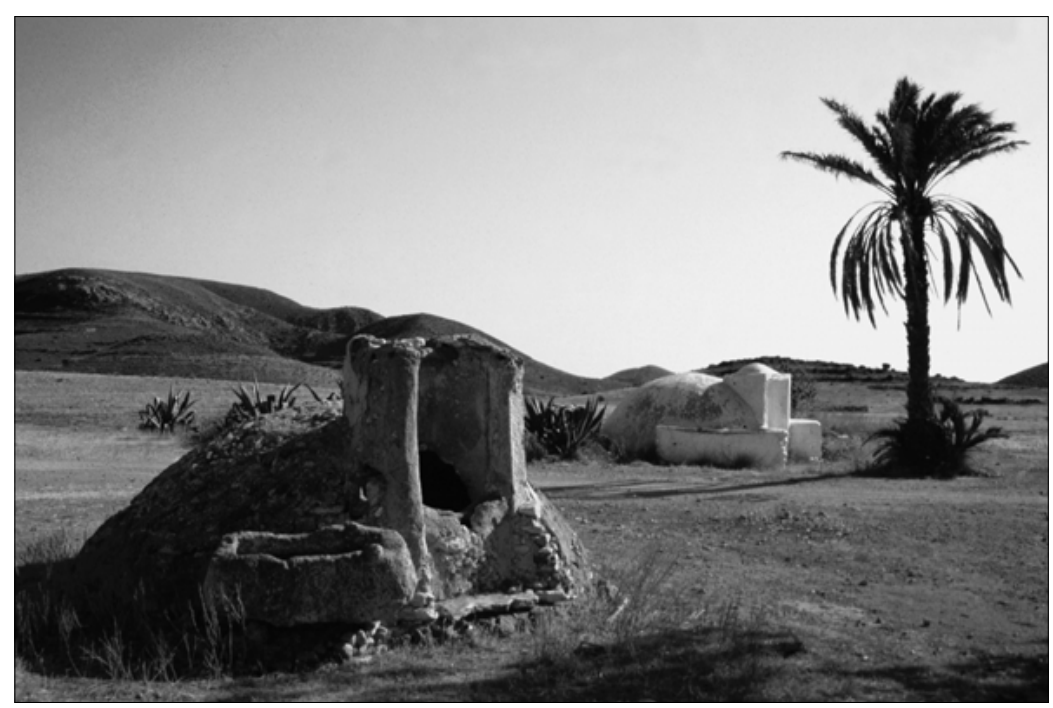

pios de Almería, Nijar y Carboneras. Se culminaba así un proceso que se había iniciado en 1999, año en que se documentaron más de 200 elementos repartidos por toda la extensión del Parque (38.000 has.).

La figura de protección elegida fue la inscripción genérica, con carácter colectivo (según el Reglamento de Protección y Fomento del Patrimonio Histórico, que desarrolla la Ley |/I99| de 3 de julio), por adaptarse a las características propias de estos bienes: elevado número y dispersos en el territorio. Este elevado número de construcciones relacionadas con la captación y almacenamiento de agua y aprovechamiento del viento se debe a las características del territorio (marcada escasez de precipitaciones y ausencia de cursos continuos de agua superficial), lo que ha llevado a la utilización extensiva de los recursos naturales.

El interés de los aljibes, norias, molinas, molinos de viento y de agua del Parque Natural de Cabo de Gata-Níjar se basa, fundamentalmente, en sus valores etnológicos (funcionales, morfológicos, tipológicos y simbólicos) al presentar un elevado número de elementos que revelan la singularidad cultural de toda esta zona árida del sureste de la Península lbérica. Estos bienes etnológicos, que son hoy marcadores identitarios para sus habitantes, permanecen en su memoria colectiva, recordándoles un pasado cercano dominado por las limitaciones que imponía un medio muy restrictivo.

Además, todos estos elementos, en su conjunto, participan hoy activamente en la materialización de la singularidad del paisaje del Cabo de Gata. La pervivencia de estas construcciones podemos entenderla a través de varios factores entre los que cabe destacar la estructura social y económica de esta zona, la estabilidad y rigidez de los sistemas hidráulicos, las técnicas de cultivo y aprovechamientos tradicionales que han permitido que, hasta muy recientemente, este conjunto de bienes hayan estado en uso continuado, modelando el paisaje con su propia estructura material y por los contrastes de vegetación que introducían a través de los cultivos asociados.

\section{La construcción de un paisaje cultural}

El Parque Natural de Cabo de Gata-Níjar se ubica en el área subdesértica del sureste de la provincia de Almería. La zona queda incluida, por sus características físicas e históricas, en el Campo de Níjar, que puede dividirse hoy en dos zonas bien diferenciadas: en la primera, el paisaje tradicional ha desaparecido prácticamente, siendo sustituido por la 
agricultura de cultivos de invernadero que ocupa una gran parte de la misma y constituye un nuevo paisaje agrario en construcción. La segunda es el propio Parque, donde el paisaje tradicional aparece más preservado.

Históricamente, la escasez de agua forzó un cultivo de secano de muy baja productividad y de precario equilibrio, con abundantes terrazas en laderas muchas veces escarpadas. Los cultivos de regadío se desarrollaron en las cortas ramblas donde podían regarse pequeñas extensiones de huertas gracias a las norias. También han dejado en el paisaje una gran impronta los cultivos de plantas tales como las chumberas y atochares, que ganaron terreno a la vegetación autóctona al implantarlos con la finalidad de completar la alimentación humana y animal, así como por intentos de cultivos industriales fracasados (el caso de las chumberas).

El poblamiento se caracteriza por un gran número de pequeños cortijos, algunas cortijadas de mayor tamaño, así como pequeños núcleos que se sitúan junto a las ramblas donde el agua se consigue de los pozos. La vivienda tradicional tiene unas características particulares: volúmenes cúbicos, una sola planta, arcos fajones, contrafuertes, etc. y edificios anejos como zahurdas, hornos, aljibes, donde por contraste a las formas cúbicas de la casa abundan las formas redondeadas. Todo en su conjunto muy adaptado a las condiciones del terreno, de donde se extraían todos los materiales utilizados en la construcción de las viviendas (piedras, pitanco, tierra, yeso y cal).

El juego que se produce entre todos estos elementos y factores, tanto naturales como humanos, articula un paisaje cultural de características excepcionales, en el cual las construcciones tradicionales tienen un importante papel. Estos elementos, sobre todo los aljibes y molinos, proporcionan una fuerte impronta al territorio constituyéndose en hitos paisajísticos por su diseminación en algunos casos y por su concentración en otros. En conjunto, estas construcciones forman un patrimonio etnológico único en Andalucía, por la elevada concentración y características tipológicas en el caso de los aljibes, por la permanencia en el uso de artes de madera en el caso de la norias de sangre, y en cuanto a los molinos de viento por ser el único lugar de la región (junto con Vejer, en Cádiz) donde los encontramos.

Los molinos, los aljibes y las norias, junto con los abundantes restos de aterrazamiento, parcelaciones, cortijos abandonados, eras, restos mineros, etc. nos hablan una costosa implantación humana sobre un medio limitante, de forma que todos estos elementos semantizan este territorio, ofreciéndonos unos significados concretos y una lectura determinada del pasado reciente de Cabo de Gata. De ahí la importancia de la conservación, rehabilitación y puesta en valor de este patrimonio.

Finalmente, y desde una lectura estética, todas estas características hacen de Cabo de Gata un conjunto visual de marcados contrastes: tonos marrones oscuros de los relieves volcánicos, los azules intensos del mar y el cielo, los ocres de la tierra y las ruinas arquitectónicas, el blanco de las construcciones, los verdes de la vegetación. Mientras que en cuanto a las formas, las ondulaciones de las sierras contrastan con la llanura del mar y las ramblas y con las líneas rectas de las antiguas terrazas de cultivo.

A continuación pasamos a presentar una descripción más detallada de los tipos de elementos que han sido objeto de inscripción en el CGPHA. Estas descripciones son resultado tanto del trabajo de campo, a través de la observación directa y de las entrevistas con los habitantes de la zona, como de la consulta de diversas referencias bibliográficas entre las que cabe hacer mención especial de la obra de Antonio Gil Albarracín (1992) Arquitectura y tecnología popular en Almería, aportación única, aún hoy, en el campo de la Arquitectura tradicional en Andalucía

\section{Aljibes: Captación y Almacenamiento del agua}

Los aljibes son sistemas de recogida y almacenamiento de agua de escorrentías procedentes de áreas lo más impermeables posible tales como laderas rocosas, caminos, superficies acostradas o incluso pequeñas microcuencas (vaguadas o barrancos).
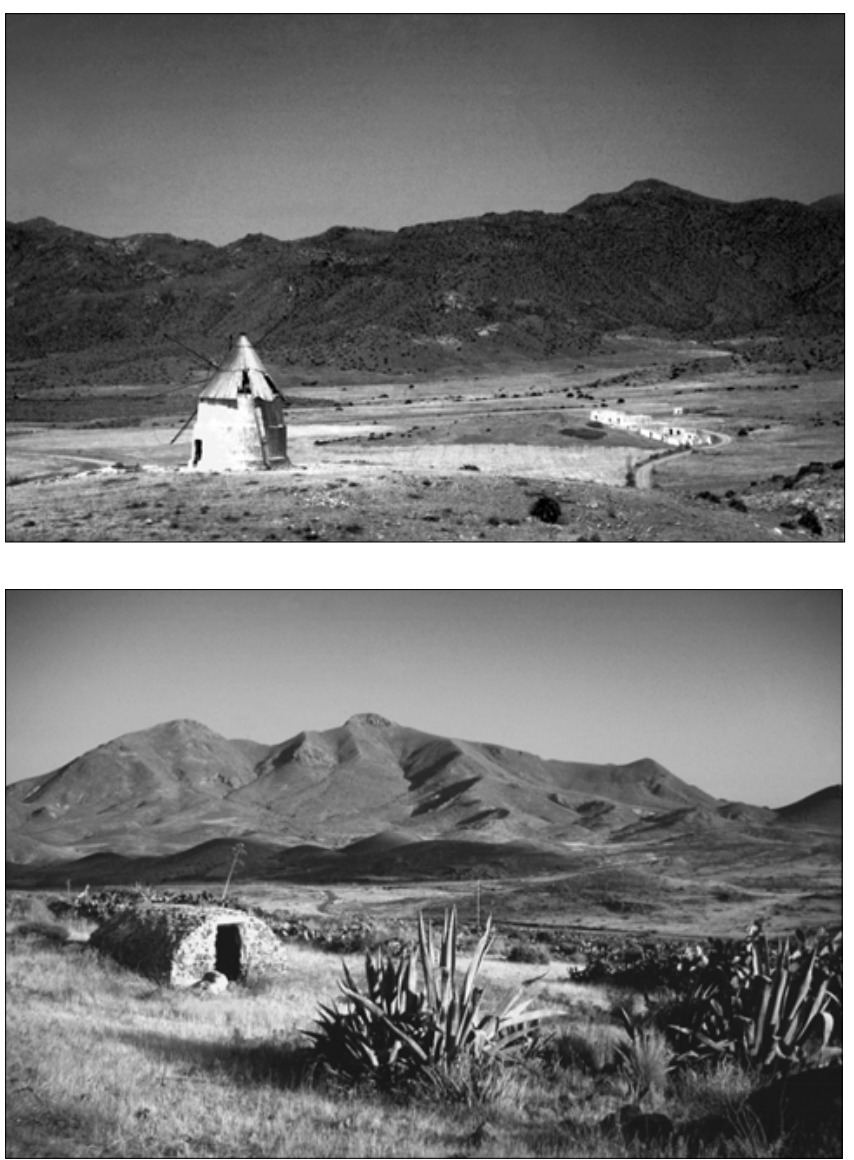

2: Campillo de los Genoveses con el Molino del Collado en primer término

3: Aljibe en el paisaje. Las Presillas Bajas 
Las aguas corrían libremente, o se dirigían mediante una construcción, hasta llegar al aljibe. Este sistema, que se encuentra extendido por todo el sudeste, constituye un modo muy eficaz de aprovechamiento del agua de lluvia en las áreas semiáridas, donde las Iluvias son torrenciales El uso principal del agua de estos aljibes ha sido el consumo doméstico y gana-

4. Aljibe de bóveda de cañón del Cortijo del Fraile

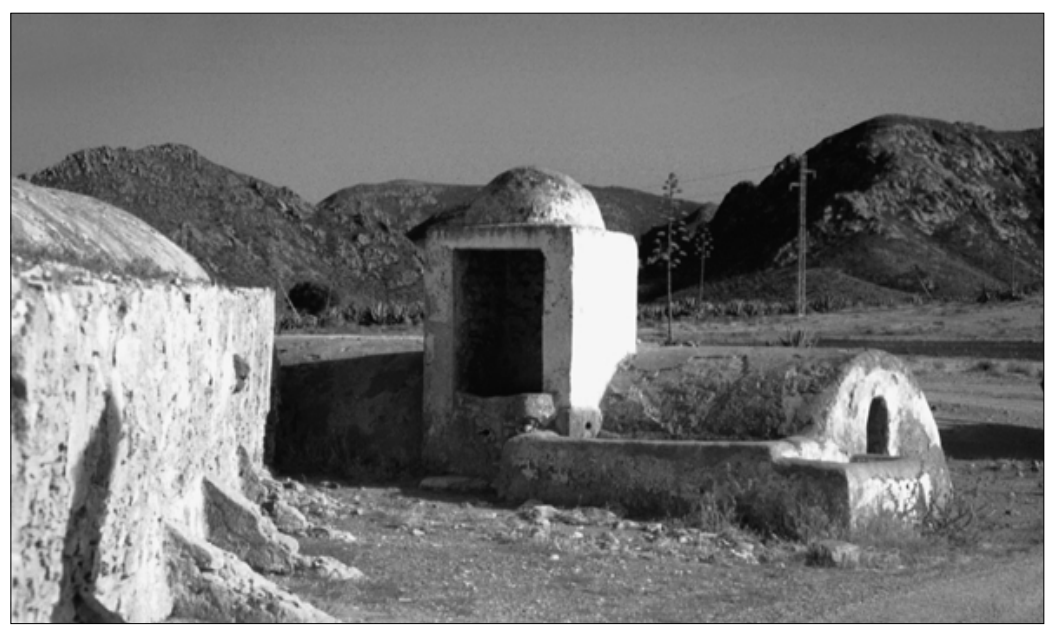

ALJIBES

Tipológicamente hay dos formas de aljibes, según el tipo de bóveda con que se cubren. Unos con bóvedas de cañón y otros, los llamados tanques o estanques, con cúpulas. Por otro lado, hay otro tipo de aljibes destacables por su función y dimensiones: los grandes aljibes ganaderos, con capacidades de 200-300 m3, que fueron construidos junto a las rutas de los ganados trashumantes que existían entre Sierra Nevada, Sierra de Gádor y de los Filabres y la zona costera (aljibe de Coyatos, aljibe del Cortijo del Cura, etc.)

Aljibe de bóveda de cañón: se construía en los lugares de paso de las aguas de lluvia, primero se excavaba un hoyo en el suelo, luego se hacían los cimientos y se levantaba un muro a base de piedra y cal, hasta llegar a la superficie. La bóveda del aljibe se realizaba por tramos con un molde de madera en forma de arco de medio punto, de unos 50 $\mathrm{cms}$. de ancho, sobre el que se encajaban las piedras que luego se rellenaban y enlucían con cal. Las paredes suelen llevar contrafuertes interiores 0 exteriores y por dentro están pintadas con almagre para evitar filtraciones. La puerta se podía ubicar directamente sobre la bóveda 0 en los frontales, con un resalte que permitía el acceso para la extracción del agua por medio de una garrucha y una pila interior que se comunicaba con los abrevaderos adosados al aljibe por el exterior. También se construía una pequeña balsa, anexa 0 cercana al aljibe, cuya finalidad es decantar el agua que discurre por la pendiente antes de entrar en el aljibe. El agua que rebosa de esta balsa entra más limpia al aljibe, pues los lodos se quedan en el fondo. En algunos casos los aljibes tienen una escalera que permite el acceso al interior para limpiar los restos de lodos que rebasan la balsa de decantación.

Aljibes de cúpula $\mathbf{o}$ estanques: se construían de forma parecida a los anteriores, en primer lugar se marcaba en la tierra un círculo. Se excavaba un hueco con la profundidad necesaria y se recubrían las paredes con piedra y mezcla formando el vaso del aljibe. Las cúpulas circulares son las más corrientes aunque se encuentran de formas diversas y con alturas interiores próximas a los seis metros. Su construcción se realizaba por aproximación de hiladas de piedras o con cerchas. Finalmente eran revocadas con mezcla dejando una puerta y una pila próxima a la puerta. Para llenar estos pilares externos, se bajaba el cubo con la garrucha, llenándolo, y una vez arriba se vaciaba en la pileta interior que comunicaba con aquellos. dero, si bien también se han dado otros usos como el forestal o minero.

Fuera de las ramblas, donde las norias extraían el agua, y de algunos lugares donde eran posibles los pozos, el resto del territorio del Cabo de Gata, que es prácticamente todo, sólo tenía disponibilidad de agua a través de los aljibes. Estos, situados cerca de las viviendas, eran destinados a proveer de agua para el abastecimiento humano, higiene personal o para lavar la ropa y abrevado de animales domésticos. Se lavaba con agua del aljibe siempre que ésta no escaseara más de lo normal, siendo frecuente ir a lavar la ropa a las norias, aunque estuvieran lejanas, para reservar el agua de los aljibes.

En la construcción participaban albañiles especializados. Así, en palabras del maestro albañil Antonio Moreno Requena (nacido en 1897), según la entrevista que realizó Gil Albarracín (1992), los pasos eran los siguientes:

\footnotetext{
"Se hacía un hueco en la tierra, se sacaba el gajo y después igual que una casa, se sacan los cimientos y llevan sus reglas en las esquinas, con su hilo; en la bóveda se ponía un molde de madera de 40 o 50 centímetros y cuando se hacía un trozo se corría el siguiente, sobre él se encajaban las lajas para hacer la vuelta, casi siempre con cal, aunque en las partes que no toca el agua también se gasta el yeso, envolviéndolo con la arena que hubiera para no gastar mucho".
}

Los aljibes eran, por tanto, puntos fijos de abastecimiento de agua. En unos casos muestran una implantación en disperso y, en otros, hay grandes concentraciones. Cuando era preciso se ubicaban en las cercanías de cortijos dispersos, o solos cuando la finalidad era abrevar ganado, tanto en sus desplazamientos trashumantes o para el ganado que salía a pastar desde cortijos cercanos. Por otro lado, en lugares como Agua Amarga, se produce una gran acumulación de aljibes (principalmente de estanques), cercanos a las viviendas. Se trata de uno de los elementos arquitectónicos más presente paisajísticamente, y sus formas redondeadas Ilegan a conformarse como una de las señas de identidad de este espacio. Respecto a su uso cabe exponer la diferencia entre los aljibes y las formas más comunes en otros lugares de abastecimiento de agua, las fuentes: mientras que éstas habitualmente se instituían en puntos de reunión y de sociabilidad, en el caso de los aljibes se trataba de una forma de captación y almacenamiento menos pública. Incluso en cortijadas como el Higo Seco o el Campillo de Doña Francisca, hay gran cantidad de aljibes particulares, muy próximos entre ellos, pero de abastecimiento individual.

En la actualidad también podemos observar cómo el aljibe es habitualmente conservado por los particulares, aún hoy, dada su utilidad en unos casos y como elemento estético e identitario por parte de nuevos residentes. 


\section{Molinos de viento}

El viento es la fuerza usada tradicionalmente en el Campo de Níjar y otros lugares de Almería para la molienda del grano. Esto era debido a la ausencia de cursos de agua permanentes que son los que posibilitan el molino hidráulico. En Andalucía sólo existen dos zonas con predominio de los molinos de viento: Vejer de la Frontera en Cádiz y los molinos almerienses. Los molinos de viento del Parque Natural de Cabo de Gata-Níjar son muy semejantes al tipo de molino cartagenero y también al manchego, diferenciándose del andaluz en la mayoría de los aspectos.

Estos ingenios requerían una gran destreza en su manejo por tratarse de un artefacto de precisión que necesita de conocimientos precisos, tanto sobre la maquinaria como sobre los vientos. Circunstancia ésta que obligaba a los molineros a tener un gran conocimiento de los vientos, al igual que los marineros, para aprovechar esta fuerza y también para evitar problemas con el mantenimiento de la maquinaria. El desastre extremo que podía producirse es que el molino "clavara la cabeza" o "hincara el pico", hecho que se produce cuando hay un cambio de viento repentino que hace que éste sople de espaldas a la orientación del molino. Cuando esto se producía significaba restituir íntegramente toda la maquinaria.

Dada la dificultad de adaptación de los molinos de viento para permanecer como artefactos harineros en su competencia con otros mecanismos de producción industrial, se hace necesaria la protección y conservación de estas máquinas como ejemplos del patrimonio ligado a la producción y el trabajo. Esto mismo, como exponíamos anteriormente, es lo que explica su mal estado de conservación. Permanecen, generalmente, las torres, habiendo perdido tanto sus maquinarias como las cubiertas e incluso forjados y escaleras. Las maquinarias, en los casos en que se conservan, no pueden reutilizarse en posibles restauraciones puesto que la madera ha quedado expuesta a la intemperie. No obstante la ubicación que se elegía para enclavar los molinos los hace especialmente atractivos para su rehabilitación y puesta en valor imprimiendo un fuerte carácter al paisaje del que forman parte.

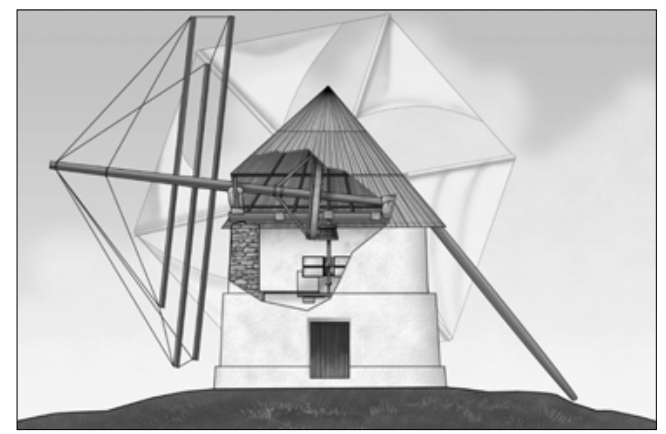

Dibujo 1: Alzado y sección del Molino del Collado de los Genoveses

5: Molino de Arriba. Cortijo del Molino en Agua Amarga 6: Molino del Fernán Pérez

\section{MOLINOS DE VIENTO}

La torre, elemento inmueble principal del molino, se construye como el resto de la arquitectura del Campo de Níjar en mampostería de piedra, cal o yeso, revocada en el exterior y el interior, y forma troncocónica, escalonada en algunos casos. El molino tiene tres plantas: la superior donde se ubica la maquinaria, la planta baja donde se ubican la romana y harinal, y una entreplanta. La planta intermedia, de poca altura (1 metro aproximadamente), que sirve para ubicar partes de la maquinaria y como almacén de cacharros. La construcción posee dos puertas enfrentadas que permitían el acceso al molino cuando las velas en movimiento tapaban una de ellas. Coronando el molino está el chapitel, obra realizada con tablas de madera, que es un elemento móvil que se gira buscando los vientos.

El funcionamiento de la maquinaria se basaba en hacer girar una rueda vertical inclinada 0 de puntería que transmite la fuerza del viento que recogen las velas. Esta rueda se engrana con otra, horizontal o linterna, que transmite la fuerza a un eje donde se encuentran las dos piedras de moler (la de abajo fija, solera, y la de arriba móvil, volandera). La energía eólica era recogida mediante velas triangulares, que partían de un eje de madera de gran tamaño atadas con sogas en todo su borde a los palos. Todo este sistema se encaraba al viento moviendo todo el chapitel del molino mediante una gran viga, llamada guía (procedente de mástiles de barcos, a veces de naufragios), que a su vez se sujetaba a unos puntos de piedra alrededor del molino para fijarlo.
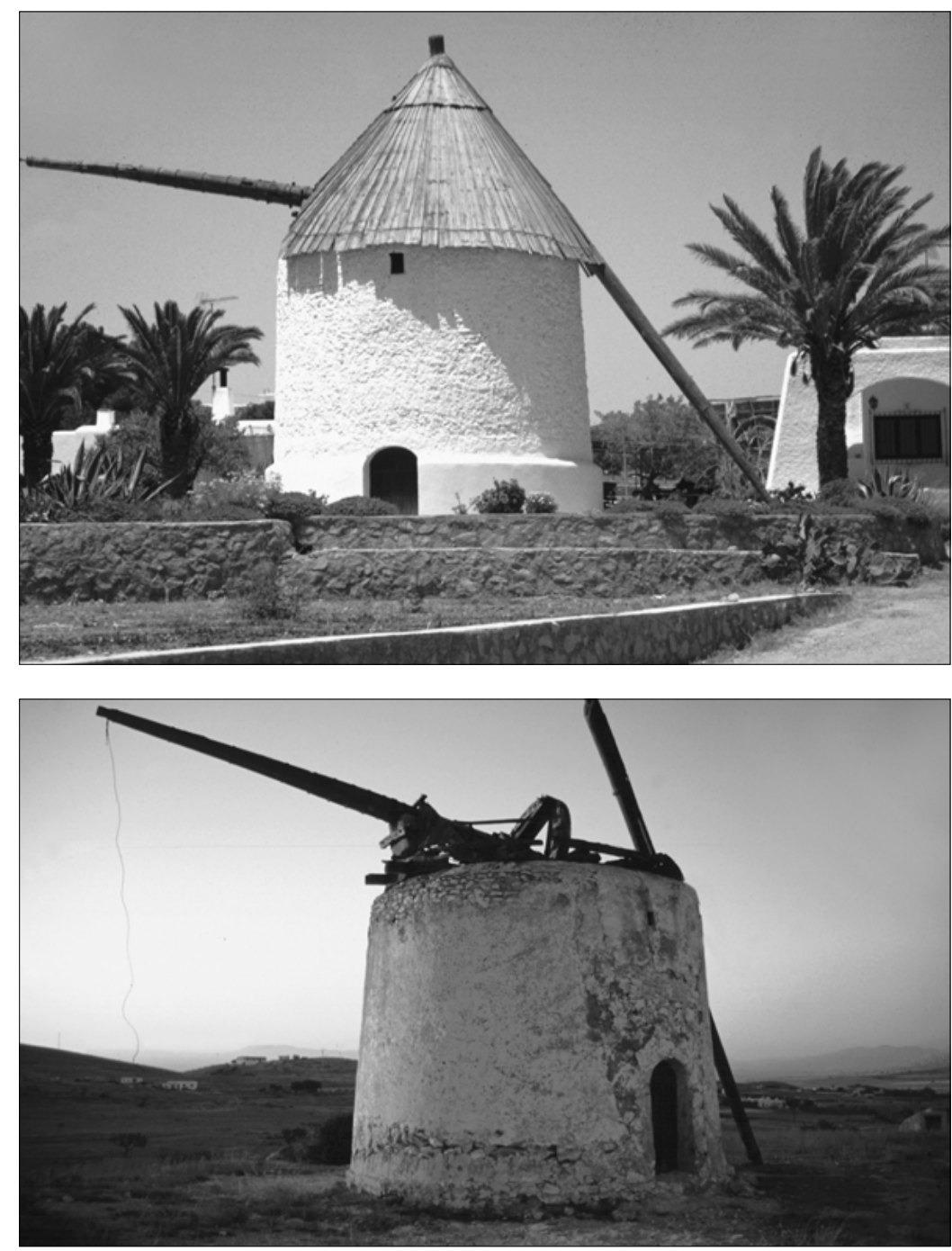

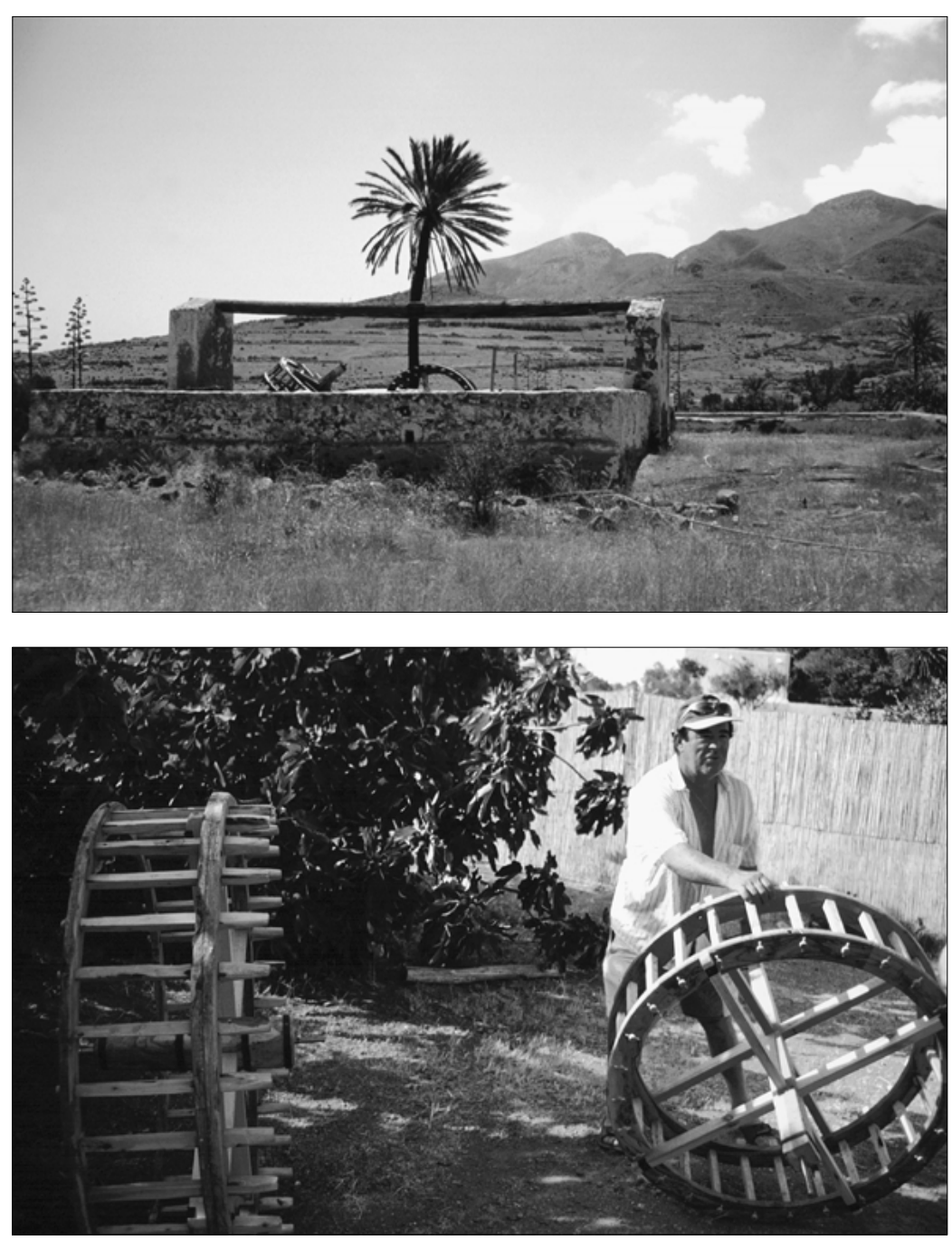

7: Noria de los Cortijos Grandes.

8: Manuel, carpintero de las Negras, es el constructor de la maquinaria de la noria del Pozo de los Frailes y el hijo del último carpintero que trabajó en las maquinarias de molinos y norias del Parque.

\section{NORIAS}

La noria se componía de una rueda de agua, la vertical, que servía para elevar los arcaduces y un arbolete. Los arcaduces de barro, con una capacidad de cuatro litros, llevaban un pequeño agujero al fondo para su vaciado una vez que dejaba de girar la noria. La fuerza motriz empleada era la de bestias de tiro, básicamente mulos, asnos y también vacas muy resistentes para este trabajo, en turnos de dos horas. En la rueda del agua se situaba la maroma que desde la misma, bajaba con los arcaduces hasta el fondo del pozo.

Tras su subida, los arcaduces vertían el agua sobre una artesilla de madera que, a su vez, vertía a una atarjea que conducía el agua desde la plataforma de la noria hasta el lavadero y la balsa contigua donde se acumulaba para el regadío de un huerto cercano.

El arbolete, o rueda horizontal, recoge la fuerza de las bestias a través del mayal, y la transmite a la rueda del agua. La necesidad de conseguir elevar las aguas a un nivel determinado para lograr el regadío por gravedad, obliga a la construcción de una plataforma, a veces de considerable altura, que son hoy, en muchos casos, el único testigo, junto con los postes, de la existencia de dichos mecanismos.

\section{Norias: Extracción de aguas subterráneas}

En la Almería semiárida son frecuentes los pozos para el aprovechamiento de las aguas subterráneas, superficiales o profundas, mediante diferentes formas de extracción. La noria es un pozo con brocal y caja alargada, casi siempre rectangulares, con una máquina para elevar el agua hasta la superficie compuesta, básicamente de dos grandes ruedas, una horizontal que movida por un animal transmite su giro a otra vertical, que provista de unas cuerdas con cangilones que suben el agua.

Las norias eran colocadas sobre una plataforma elevada y localizadas en las zonas abancaladas junto a las ramblas, buscando las corrientes subterráneas de aguas poco profundas. El agua era acumulada en una balsa y luego, si la noria y la balsa eran comunales, mediante un sistema de turnos de riego llamados tandas, se regaban los bancales.

Las norias, con un origen impreciso, son parte de un complejo hidráulico formado por el pozo, la propia noria, las balsas, el lavadero y la huerta próxima. El desfase tecnológico de las norias hizo que fuesen sustituidas por bombas y motores de gasoil o eléctricos permaneciendo hoy en un estado de ruina progresiva como norias, aunque muchas siguen usándose como pozos. A esta situación escapa la notable excepción de la noria del Pozo de los Frailes, restaurada por la Consejería de Cultura.

Las norias han sido durante mucho tiempo el único medio de poner en producción agrícola algunas tierras, ya que eran la forma de extraer mecánicamente el agua desde profundidades considerables en muchos casos. Sus restos, hoy, nos hablan de un paisaje agrario prácticamente desaparecido, donde siguiendo el cauce de las ramblas se suceden las pla-

Dibujo 2: Planta y sección de la noria del Pozo de los Frailes
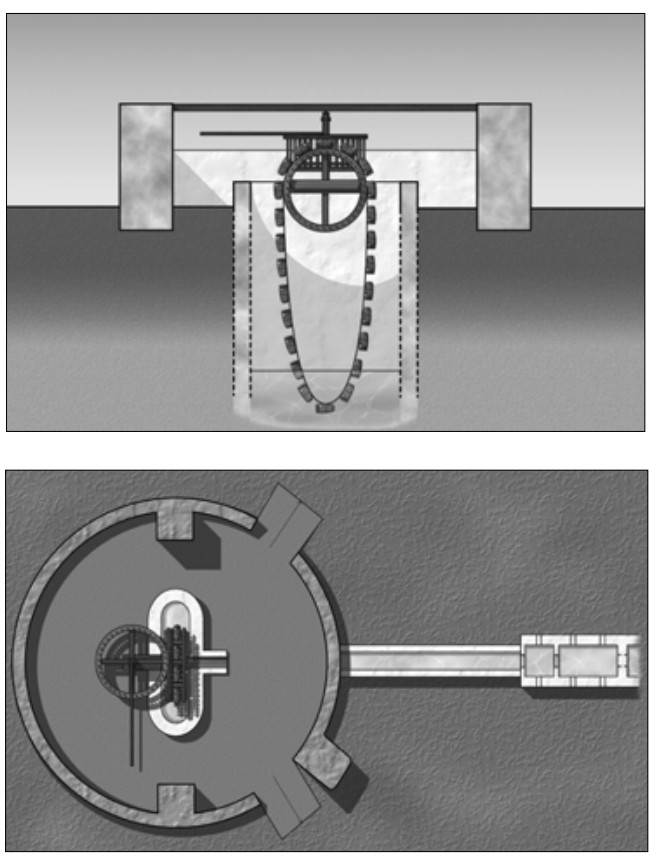
taformas de las norias con su balsa y las parcelas aterrazadas (bancales) que forman unas pequeñas franjas de regadío, que, aunque precariamente, posibilitó el asentamiento humano sobre un terreno extremadamente seco.

Por otro lado, hay que destacar el papel de las norias en esta zona como lugares de encuentro, ya que eran el lugar más habitual para lavar la ropa, como se ha indicado más arriba, por la necesidad de preservar el agua de los aljibes. Al ser estas particulares, había que pagar por su uso, pero al tiempo se convertían, como todos los lavaderos públicos tradicionales, en un lugar de sociabilidad femenina y de encuentros también entre hombres y mujeres.

Por último, es interesante hacer referencia a una curiosa maquina, la noria de viento o molina. Se trata de un artefacto cuyo mecanismo es una fusión de la noria y del molino de viento, usada para la extracción de agua. Básicamente es un molino, junto a un pozo, al que se le sustituyen las ruedas de molturación por un mecanismo para mover en su lugar una cadena sin fin donde están los arcaduces, que a veces bajaban hasta 40 metros de profundidad. En el Cabo de Gata solo existen los restos de uno de estos elementos, la molina del Cortijo de San Antonio, aunque existía otra en Balsas Blancas y algunas más en el resto del Campo de Níjar.

\section{Pervivencias: El patrimonio etnológico en la construcción actual del paisaje de Cabo de Gata}

La cultura tradicional que produjo estas construcciones ha ido paulatinamente desapareciendo en los últimos cuarenta años, dando paso a nuevas formas de aprovechamiento económico y, en general, a nuevas formas de vida. En este nuevo contexto, las norias, los molinos y los aljibes del Cabo de Gata han ido reencuadrándose de diferentes maneras, con nuevas funciones, pero permaneciendo inscritos con fuerza en el actual paisaje del Parque.

En los últimos años, sobre este territorio han venido a incorporarse nuevos factores en la construcción del paisaje. El primero de ellos es el turismo que se ha desarrollado sobre pequeños núcleos en la zona costera, pero en unos niveles muy inferiores a los del resto del litoral español. Pese a este desarrollo turístico limitado, las construcciones generadas no siempre se han adaptado a las características tipológicas y morfológicas tradicionales.

El segundo factor que incide en el paisaje es la nueva agricultura de invernaderos. El paisaje tradicional del Campo de Níjar ha quedado fuertemente transformado por el cultivo bajo plásticos, que en la actualidad presiona sobre los límites del Parque, produciéndose algunos casos de invernaderos ilegales en el interior del mismo.
Otro grupo que hoy actúa sobre el paisaje, son los nuevos residentes, personas llegadas al territorio del Parque atraídas por el exotismo de la zona. Fenómeno este ligado a los trabajos de pintores, fotógrafos, escritores y cineastas que, entre otros, han publicitado una determinada imagen de este espacio. Son residentes permanentes y estacionales que aportan su propia perspectiva sobre lo que es y debiera ser el paisaje de Cabo de Gata.

La población autóctona emigró en una gran proporción, ya desde principios de siglo, hasta Argelia y Marruecos (en la llamada "emigración golondrina") y posteriormente hacia el norte de España y Europa Central, como el resto del centro y sur peninsular. Esto supuso un abandono de gran parte del territorio, de los cortijos más aislados y de la agricultura tradicional, con la consiguiente transformación del paisaje. Con la revitalización económica, parte de la población autóctona se suma a la actividad turística o a la nueva agricultura, al tiempo que regresan parte de los emigrados que rehabilitan sus antiguas casas.

Por último tanto los ayuntamientos (Níjar, Carboneras y Almería) como la figura del Parque Natural aportan sus propias concepciones sobre la mejor gestión de este territorio.

Estos son los principales grupos de acción que intervienen hoy sobre el paisaje. Todas estas posturas suponen percepciones, pero también actuaciones diferentes sobre el territorio, no siempre compatibles, que se ponen de manifiesto en el paisaje.
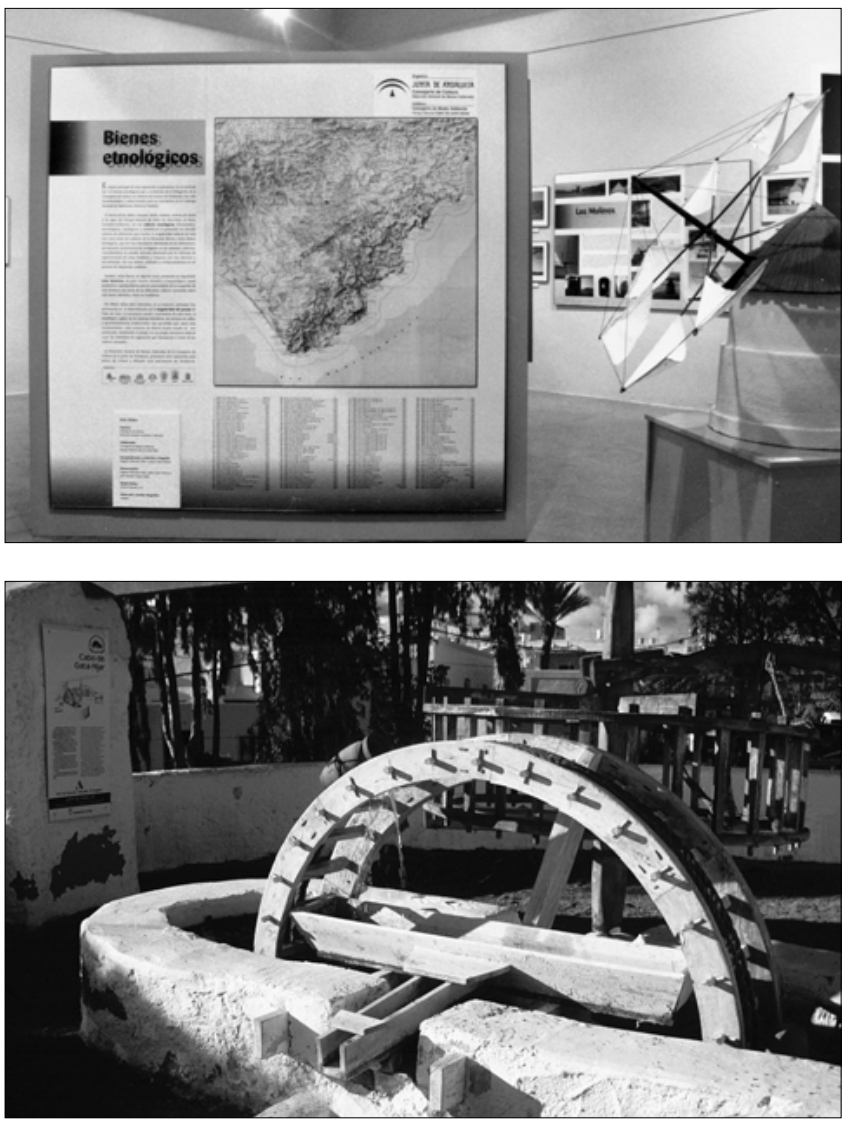

9: Exposición permanente sobre los bienes etnológicos del Parque Natural de Cabo de Gata-Níar. organizada por la Consejería de Cultura y radicada en Rodalquilar desde mayo de 2001

10: Noria del Pozo de los Frailes, reconstruida por la Consejería de Cultura 
En este panorama general, los bienes etnológicos, las norias, los molinos y los aljibes se integran en el actual paisaje del Parque Natural perviviendo de tres formas básicas:

- Como elementos conservados, gracias al mantenimiento por parte de sus propietarios, por seguir en uso, por sus valores estéticos o por el mantenimiento de la tradición y el recuerdo. También por el esfuerzo de la Administración a través de la protección, tal es el caso de la inscripción colectiva en el CGPH aquí tratada. A través de este tipo de protección se ha conseguido poner de relieve un gran conjunto de elementos que permite superar la imagen de singularidad del bien patrimonial (ligada a lo monumental), contribuyendo al mantenimiento de una gran parte de estos elementos tan importantes para la conformación de éste paisaje. Por último hay que hacer mención también a la restauración por parte de las administraciones, tal es el caso de la noria del Pozo de los Frailes.

- Por otro lado, las formas de las construcciones tradicionales quedan evocadas en las nuevas edificaciones. Unas veces a través de elementos constructivos como chimeneas, estancias, salientes, ornamentos, etc. que usan cúpulas y bóvedas de cañón, recordando los aljibes. Otras, directamente, a través de edificaciones que imitan aljibes, molinos, e incluso norias. En otros casos se han conservado parte de los elementos tradicionales asignándoles nuevos usos, tal es el caso de algunas balsas de noria convertidas en piscinas, o el andel de alguna noria convertido en terraza de un complejo turístico.

- Como ruina, en tanto que testigos de formas de ocupación del territorio ya desaparecidas, y por ser evidencia en sí misma del fenómeno del abandono del mismo por sus pobladores durante buena parte del siglo XX Estas ruinas, que salpican todo el Parque, se constituyen hoy en uno de los elementos paisajísticos de mayor impronta, integrándose en el paisaje y otorgándole la fuerza del recuerdo.

Por ultimo hay que subrayar que todo este conjunto patrimonial se encuentra dentro de un Parque Natural, que a su vez se inserta en una comarca, el Campo de Níjar, que contiene también un elevado número de estos bienes, sometidos a las tensiones propias de la evolución del paisaje agrario (más aún aquí que se trata de una zona de expansión de invernaderos) y dónde este tipo de patrimonio desaparece aceleradamente. Por esta razón, entre otras, la figura del Parque Natural, además de establecerse como un ente de conservación, tiene el reto de constituirse en laboratorio de experiencias que busque la armonización de los distintos elementos que conforman el paisaje, teniendo la posibilidad, incluso la vocación, de generar fórmulas que puedan ser exportadas fuera de él, por su carácter ejemplar una vez contrastada su eficacia.

\section{Bibliografía}

BOILLON, DIDIER, 199| "Le paysage: un patrimoine à gère". Etudes Rurales, 121 - 124: 197-205.

BOILLON, DIDIER, 1998 "L'Inventaire des paysages des parcs naturels régionaux". En Arias Abellán, Jesús y Fourneau, Francis El paisaje mediterráneo. Granada: Universidad.

CARA BARRIONUEVO, L. 1996 “.... Y mudaban de pastos con sus ganados". Una aproximación histórica a la ganadería almeriense". En Sánchez Picón, A. (Ed.) Historia y medio ambiente en el territorio almeriense. Almería: Universidad. Págs.: 49-82.

CARA BARRIONUEVO, L.; Rodríguez López, J. M. 1989 "El ámbito económico del pastoralismo andalusí. Grandes aljibes ganaderos en la provincia de Almería". En AA.VV. El agua en zonas áridas: arqueología e história. Actas del I Coloquio de Historia y Medio Físico. Almería: Instituto de Estudios Almerienses.

CARO BAROJA, J. 1952 "Disertación sobre los molinos de viento". Revista de Dialectología y Tradiciones Populares, VIII: 21 2-366.

GIL ALBARRACÍN, A. 1992 Arquitectura y tecnología popular en Almería. Almería: GBG.
MOLINA, P.; Checa, F.; Muñoz Muñoz, J. A. 1998 "La cultura tradicional del agua. Tecnología hidráulica y simbolismo en los Campos de Níar". Demófilo, 27: 167-198.

PROVANSAL, D. 1993 "El parque Natural de Cabo de GataNíar: De la percepción estética de un paisaje a la transformación social". Gonzalez Turmo, I (Coord.) Parques Naturales Andaluces. Conservación y Cultura. Sevilla: Consejería de Cultura. Págs.: 47-5I.

PROVANSAL, D.; MOLINA, P. (Eds.) 199| Etnología de Andalucía Oriental I. Parentesco, agricultura y pesca. Barcelona: Instituto de Estudios Almerienses y Anthropos.

PROVANSAL, D.; MOLINA, P. 1989 Campo de Nijar: Cortijeros y areneros. Almería: Instituto de Estudios Almerienses.

TORRES MONTES, F. 1993 "Los antiguos molinos de viento en el campo de Níar. Estudio etnográfico-lingüistico". En AA. W. Homenaje a Elena Pezzi. Granada: Universidad. Pág.: 275-289.

VAN WeSEMAEL, B.; POESEN, J.; Solé Benet, A.; Cara Barrionuevo, L.; Puigdefábregas, J. 1998 "SSiguen siendo útiles los aljibes ganaderos en la provincia de Almería?". Investigación + Gestión, 3: 207-216. 